\title{
ESCREVER A RAIZ DA ESCRITA: SOBRE O TEMPO NA TEXTUALIDADE LLANSOL
}

Jonas Miguel Pires

Samudio*

\author{
* alfjonasss@yahoo.com.br
Mestrando em Teoria Literária (bolsista CAPES) no \\ Programa de Pós-Graduação Mestrado Acadêmico em \\ Letras da Universidade Federal de Uberlândia, com \\ a pesquisa: "Do sexo de ler este luar: a poética da \\ travessia em Maria Gabriela Llansol", sob orientação \\ do Prof. Dr. Paulo Fonseca Andrade.
}

RESUMO: Propomos a leitura de um fragmento da obra Causa amante (1996), de Maria Gabriela Llansol, cotejada com outros textos da autora - como fragmentos dos diários considerando sua proposição do conceito e da experiência de tempo, marcada pela escrita. Para tanto, recorremos a Giorgio Agamben (2009, 2012), Walter Benjamin (2012) e Martin Heidegger (1991), sublinhando que tais autores apresentam reflexões que possibilitam um questionamento da noção tradicional de tempo cronológico, auxiliando-nos em nossa leitura de Llansol, ao nos indicar que, para além da passagem do tempo, há outras experiências de temporalidade, como simultânea e espacial realizadas na "Textualidade Llansol", que se referem não apenas a um elemento de sua constituição, mas à técnica de escrita chamada "sobreimpressão".

PALAVRAS-CHAVE: tempo; escrita; Maria Gabriela Llansol.

RESUMEN: Proponemos una lectura de un fragmento de la obra Causa amante (1996), de Maria Gabriela Llansol, cotejados con otros textos de la autora - como fragmentos de los diarios - considerando su concepción y experiencia del tiempo, marcado por la escritura. Por lo tanto, se recurre a Giorgio Agamben (2009, 2012), Walter Benjamin (2012) y Martin Heidegger (1991), por creer que estos autores presentan reflexiones que permiten que cuestionemos la noción tradicional del tiempo cronológico, y que esto nos ayuda en nuestra lectura de Llansol, indicandónos que, además del transcurso del tiempo, hay otras experiencias como la temporalidad simultánea y espacial, que se realiza en la "Textualidade Llansol", y que se refiere no sólo a un elemento de su constitución, pero a la técnica de escrita llamada "sobreimpressão"

PALABRAS-CLAVE: tiempo; escrita; Maria Gabriela Llansol. 
1. LLANSOL. Inquérito às quatro confidências. p.66.

2. Os termos-conceitos presentes na obra de Maria Gabriela Llanso são grafados, a partir daqui, entre aspas.
Os bons escritores fazem os maus diários. Aceito fazer um mau diário.

Maria Gabriela Llansol

Tempo e escrita. Escrita como fuga do tempo, tempo como experiência exterior à escrita. Tempo: passagem, desvanecimento, velocidade hostil, destinação irrefutável. Escrita: pulsão, desejo, sulcagem no real, esperança de duração.

Entre tempo e escrita, um ressalto de frase, um silêncio, e uma tentativa de dizer. Maria Gabriela Llansol nos diz:

$\mathrm{O}$ texto dobra, efeito de colagem. $\mathrm{O}$ texto suspende o sentido, à espera do dizer exacto. Há frases que só completei anos depois; há frases que, no limiar dos mundos, não devem ser escritas por inteiro; há frases cujo referente de sentido será sempre obscuro. Se eu soubesse escrever um texto sempre limpo, tiraria o traço.

Perdido, muitas vezes, está o referente. Também o sentido pode ser abandonado, caso se coloque a serviço da "impostura da língua"':

Nunca olhes os bordos de um texto. Tens que começar numa palavra. numa palavra qualquer se conta. Mas, no ponto-voraz, surgem fugazes as imagens. Também lhes chamo figuras. Não ligues excessivamente ao sentido. A maior parte das vezes, é

EM TESE impostura da língua. Vou, finalmente, soletrar-te as imagens deste texto, antes que meus olhos se fatiguem. ${ }^{3}$

Diante dessas afirmações, podemos nos perguntar sobre a relação, estabelecida na "Textualidade Llansol", entre a referência ao tempo - que se apresenta, por exemplo, na obra diarística de Llansol e na marcação de datas presente nas obras da autora - e a escrita: Por que, diante do abandono da referência e do sentido, o tempo é, estrita e frequentemente, demarcado nos textos de Maria Gabriela Llansol?

Afirmamos, à guisa de hipótese, que a marcação de tempo é incorporada na escrita que pretende realizar a vida - sob o estatuto da grafia da vida, da biografia, da vida escrita:

[...] a vida escrita é a vida que se escreve, mesmo que não se saiba. Como a lesma que deixa uma gosma viscosa em seu caminho. Como a lágrima que fala em seu silêncio de dor ou alegria. Ou o rápido traço no ar que faz o pássaro, da gaiola ao galho, ao ar que se risca com sua fuga, no movimento-escrita reto ou sinuoso, como letras que se encaminham e se ligam (BRANDÃO, 2006: 23)

Assim, seguimos a reflexão de Cinara de Araújo (2008) que denomina, a partir de Silvina Rodrigues Lopes $(1988)^{5}$ biografia como método ao modo de escrita de Maria Gabriela Llansol, um método que incorpora o diário como a forma de realização da escrita.
3. LLANSOL. Um beijo dado mais tarde. p.112.

4. BRANDÃO. $A$ vida escrita. p.23

5. RODRIGUES LOPES, Silvina. Teoria da despossessão: ensaio sobre textos de Maria Gabriela Llansol. Lisboa: Black Son Editores, 1988. 
6. LLANSOL. A escrita sem impostura. p.48, destaques no original.

7. cf. CASTELLO BRANCO. Nuvens de pensamento branco. p. 230

8. LLANSOL. Um falcão no punho. p.52.

9. cf. CASTELLO BRANCO. Nuvens de pensamento branco. p.244.
Objetivando, pois, refletir a partir do posicionamento inicial acima expresso, efetivaremos, neste ensaio, uma breve apresentação da "Textualidade Llansol”, partindo de trechos da obra. A seguir, analisaremos um fragmento de Causa Amante (1996) que, parece-nos, explicita a relação entre o tempo e a escrita na proposição llansoliana.

Quatro palavras nos são importantes, para uma breve e inicial compreensão do específico da "Textualidade Llansol"; além disso, são importantes como diretrizes para a "legência" - o gesto de leitura que este texto pede, distanciado da decodificação e da hermenêutica, e posto como possibilidade de encontro e afectus - numa perspectiva spinozista -, em que os sentidos se abrem em leque e não reduzem a leitura. Leiamos, pois, algumas palavras de Maria Gabriela Llansol:

I. "quando me perguntam se escrevo ficção tenho vontade de rir Ficção? Personagens que acordam dormem, comem? Não, não tenho nada a ver com isso. Para mim, não há metáforas. Uma coisa éou não é. Não existe o como se."'. Não há metáfora, ou seja, o texto não pede uma prática de leitura fundada no imaginário ${ }^{7}$

II. “não há literatura. Quando se escreve só importa saber em que real se entra, e se há técnica adequada para abrir caminho a outros" ${ }^{\prime \prime}$. Não há literatura, e esta escrita move-se em direção não à representação do real, mas à sua apresentação
III. "sem provocação [...]: a textualidade é realista, se souber que, neste mundo, há um mundo de mundos, e que ela os pode convocar, para todos os tempos, para lá do terceiro excluído, e do princípio de não-contradição" ${ }^{10}$. Novamente, agora pela via-afirmativa, o texto é dito como realista e, além disso, como participando do movimento do terceiro-excluído, como a nos dizer que sua leitura se faz de modo diferente daquele previsto pela lógica aristotélica (silogística, do universal para o particular e sem contradição).

IV. "ler é nunca chegar ao fim de um livro respeitando-lhe a sequência coercitiva das frases, e das páginas. Uma frase, lida destacadamente, aproximada de outra que talvez já lhe correspondesse em silêncio, é uma alma crescendo"11. Desse modo, a leitura do texto de Llansol - a "legência", como a denominaremos, com a autora, a partir de aqui - pede uma atitude outra com o texto: deixar-se fulgorizar, e permitir que o pensamento vá a zonas interstícias, como o "sexo de ler" o promove.

Para efetuar, desse modo, a legência de nosso "sexo de ler", este texto se abre como uma "alma crescendo", e se abre o texto como sentidos em leque, não como decodificação-interpretação. Talvez, ele nos pede uma leitura como aquela que nos ensina Lacan:
10. LLANSOL. Para que o romance não morra. p.121.

11. LLANSOL. Amar um cão. p.45, destaques no original. 
12. LACAN. O seminário: livro 20. p.43.
Para me fazer compreender, vou tomar como referência o que vocês leem, o grande livro do mundo. Vejam o voo de uma abelha. Ela vai de flor em flor, ela coleta. O que vocês aprendem é que ela vai transportar, na ponta de suas patas, o pólen de uma flor para o pistilo de outra flor. Isto é o que vocês leem no voo da abelha. No voo de um pássaro que voa baixo - vocês chamam isto um voo, mas, na realidade, é um grupo, num certo nível - vocês leem que vai haver tempestade. Mas será que, eles, leem? Será que a abelha lê que ela serve à reprodução das plantas fanerógamas? Será que o pássaro lê o augúrio da fortuna, como diziam antigamente, quer dizer, da tempestade? ${ }^{12}$

Assim, somos postos diante de um texto que abandona a referência - segundo a relação objeto-representação -, a interpretabilidade - de acordo com a relação referente-metáfora. Diante desta experiência de abertura - de sentidos, de espaço literário, pensamos com Maurice Blanchot (2011) destacamos que o tempo, aqui, não é, pois, metaforizado ou representado como uma exterioridade enfrentada pelo sujeito escrevente. Antes, o tempo, na “Textualidade Llansol”, é aquilo que a escrita, verdadeiro animal, pode perfurar e modificar substancialmente, fundando uma outra temporalidade e, desse modo, uma outra forma de constituição humano-cultural tal como afirma Giorgio Agamben, em "Tempo e História: Crítica do Instante e do Contínuo": "toda cultura é, primeiramente, uma certa experiência do tempo, e uma nova cultura não é possível sem uma transformação desta experiência"13 sabendo-se que a proposta de Maria Gabriela Llansol não é, tão-somente, uma reflexão-proposição cultural, mas, antes e intrinsecamente, um pensamento sobre o humano em suas relações com as outras "formas do vivo" - que são, segundo a autora, os animais, as plantas, os objetos -, uma nova relação marcada pela não-hierarquização e pelos encontros instituidores de novos começos efetuados na escrita.

Avançando algumas palavras na compreensão llansoliana acerca do tempo, propomos, agora, uma "legência" de um fragmento de Causa Amante (1996) ${ }^{14}$, em que é apresentado, parece-nos, um "pensamento verdadeiro" sobre a escrita e o tempo:

era uma vez um animal chamado escrita, que devíamos, obrigatoriamente, encontrar no caminho; dir-se-ia, em primeiro, a matriz de todos os animais; em segundo, a matriz das plantas e, em terceiro,

a matriz de todos os seres existentes.

Constituído por sinais fugazes, tinha milhares de paisagens, e uma só face,

nem viva, nem imortal. Não obstante, o seu encontro com o tempo apaziguara a velocidade aterradora do tempo, esvaindo a arenosa substância da sua imagem. ${ }^{15}$

Lemos uma "cena fulgor". Lemos, outrossim, uma cena que nos diz do encontro entre a escrita e o tempo. Lemos, ainda,
13. AGAMBEN. O Tempo e a História. p.109.

14. A primeira edição de Causa Amante é de 1984. A consultada, nesse trabalho, é de 1996.

15. LLANSOL. Causa amante. p. 160. 
16. Maria de Lourdes Soares afirma, por exemplo, que nos diários Llansol apresenta à concentração lírica ou à suspensão mística (SOARES. diário de Llansol. p.50). que a escrita é um animal, anterior ao encontro que, com ele, possa se efetivar na vida de qualquer um, escritor e não. Lemos, ademais, que o animal escrita é matriz de todas as formas do vivo, incluindo, dentre esses, os outros animais, as plantas e todos os outros seres, o que nos faz pensar no caráter matricial de plasmação de todo o existente, segundo uma ordem escritural. Lemos, também, que o animal escrita não tem corpo, ou, talvez, que seu corpo são os sinais que o constituem, sinais de fragilidade intrínseca, sinais vinculados ao passajar próprio dos gestos escriturais. Com corpo esfacelado, fragmentário, o animal tem uma face que se constitui em uma relação temporal específica, visto que é "nem viva, nem imortal". Igualmente, dá-se um encontro entre o animal e o tempo que, agora, a partir e nesse encontro, tem sua "substância arenosa", por meio do apaziguamento, a se esvair. A face do animal escrita, seu ponto de embate com o que se apresenta a si, se constitui, pois, por uma temporalidade de outra qualidade ${ }^{16}$, fora da costumeira dicotomia "instante", evocado pelo "viva" e pelo "arenosa" - visto que, no tempo, a vida é um instante passageiro e finito, e as areias do tempo são imagem do quão passageiros e contabilizáveis são os instantes -, e "contínuo", trazido à tona pelo "imortal" e pela "substância" - já que, pensando-se em uma temporalidade fechada, imortal refere-se a um aspecto contínuo, vinculado, talvez, à ideia de eternidade, assim como "substância" nos reporta à materialidade em sua forma e constituição por meio de características específicas ${ }^{17}$. Nesse sentido, o fragmento nos apresenta uma relação qualitativa entre escrita e tempo, de modo que, nos parece, a "Textualidade Llansol" nos aproxima da crítica, efetivada por Giorgio Agamben, à respeito do tempo compreendido como "Instante" e como "Contínuo"18.

Após essa prévia reflexão sobre tempo e escrita, podemos nos perguntar, aproximando, do fragmento de Causa Amante (1996), a constituição, em inúmeras obras de Maria Gabriela Llansol, do caráter diarístico: qual qualidade do tempo a “Textualidade Llansol”, em suas diferentes e específicas realizações textuais, nos apresenta como possibilidade de experiência? Além disso, destacando que "consigo escrever apenas em Diário"19 e que se pode "colocar este Diário, que diz respeito à ordem figural do quotidiano, ao lado de O livro da Comunidades, Da Sebe ao Ser, e de Causa Amante" ${ }^{20}$ - trecho que evidencia a aproximação entre o diário e outros títulos publicados, estes sem formatação diarística -, afirmamos a indiferenciação, em Maria Gabriela Llansol, entre a escrita dos diários e o restante da obra.

Perseguindo uma palavra que nos sustente a reflexão sobre o tempo, a partir do fragmento lido, percebemos que o início do texto marca uma relação temporal com o pretérito: "era uma vez". Igualmente, o fragmento nos diz que o tempo não tem face, nem continuidade, nem instantes que lhe sejam substanciais. O tempo tem, tão-somente, uma imagem
17. Cf. "Substância" em Dicionário Aulette. Disponível em: $<$ http://aulete.uol.com.br/ subst $\%$ C3\%A2ncia>. Acesso em 12.jul.2013.

18. Propondo uma reflexão sobre o Tempo, Giorgio Agamben realiza uma crítica das concepções de tempo em suas relações com o conceito de História, perpassando, por exemplo, pelas temporalidades cíclicas da antiguidade grega, pela linearidade teleológica do tempo no cristianismo, para afirmar que a compreensão tradicional de Tempo se assenta sobre o binônmio "instante" e "contínuo", pois é tomado pela concepção numérica da respeito do mesmo. Agamben (2012), assim, afirma a necessidade de "trazer à luz o conceito de tempo implícito na concepçao marxista da história" (p.109) (cf.AGAMBEN, Tempo e História: Crítica do Instante e do Contínuo. Infância e História, p.109-126).

19. LLANSOL. Um falcão no punho. p.62.

20. LLANSOL. Um falcão no punho. p.64, destaques no original. 
21. GRIMM. O pescador e sua mulher. p.36.

22. GRIMM. O pequeno polegar. p.61.

23. GRIMM. A bela adormecida. p.56. a escrita, animal, estabelece um encontro que apazigua a "velocidade aterradora” do tempo, ou seja, a escrita é demarcada como um modo de se relacionar com o tempo, não como fuga, mas como enfrentamento, confronto e transformação.

1. "era uma vez um animal chamado escrita"

"Era uma vez um pescador e sua mulher..."

"Estava uma vez um pobre lenhador..."22

"Certa vez, havia um rei e uma rainha..."23

"Naquele tempo, Jesus disse aos seus discípulos..."

Os trechos acima apresentados nos recordam que determinados tipos de texto, lidos em momentos bastante posteriore à sua origem que, por vezes, está perdida num evento remoto, instituem uma temporalidade destacada da fixidez do passado, do presente e, igualmente, do futuro. São textos que, de certo modo, constituem-se em relatos originantes, origens tais que, definitivamente, estão radicadas no cotidiano daqueles aos quais elas dizem respeito: camponeses medievais, cristãos que participam da liturgia cotidiana. Essas formas textuais não cessam de evocar um tempo para um outro tempo, tempo ausente que nos fala de uma intimidade cheia de presente, conforme parece nos dizer Maurice Blanchot:

EM TESE

BELO HORIZONTE

V. 19

N. 3

SET.-DEZ. 2013
[...] a "ausência de tempo" para a qual nos conduz a experiência literária não é, de modo algum a região do intemporal, e, se pela obra de arte somos chamados ao abalo de uma iniciativa verdadeira (a uma nova e instável aparição do fato de ser), esse começo nos fala na intimidade da história, de uma maneira que talvez dê chance a possibilidades históricas iniciais ${ }^{24}$.

Novas e iniciais possibilidades históricas, nos afirma Blanchot (2005). Ler, pois, o "era uma vez um animal" é ser reportado a um anúncio do começo dado no ato de legência; e se o animal é "chamado escrita", passamos a ver que o começo é qualitativamente ligado às figuras que, neste texto, "foram convocados para um acto de recomeço" ${ }^{25}$, para encontros de confrontação que possam dar início a novos ciclos de pensamento, sob a escrita. Em suma, o animal diz respeito àquilo que, antes do encontro com qualquer escritor/escrevente, existe como prevalente: a própria escrita, seja como forma de cultura, seja como experiência que se dá em evento de encontro com qualquer sujeito que, sob o seu signo, deseja se colocar; em suma, de acordo com Llansol, a escrita subsiste àquele que escreve, selvagem e próxima das formas do vivo, não apenas dos seres dotados de capacidades racionais.

Assim, podemos falar, ainda próximos do pensamento de Blanchot (2005), que a qualidade do tempo, conforme apresentada na "Textualidade Llansol", reporta-nos a uma promessa de ausência, um já dado que não se conclui - como o
24. BLANCHOT. O desaparecimento da literatura. p.290.

25. LLANSOL O extremo ocidental do Brabante. p. 130 . 
26. LLANSOL. Um beijo dado mais tarde. p.15, destaques no original.

27. LLANSOL. Livro de horas I: Uma data em cada mão. p.23. escrito que, se não for lido, será meio passo no caminho -, um ponto temporal sempre posto para o futuro e a incerteza, como nos afirma o texto:

Creio que meus textos sabem muito mais; eles não estão atrás no meu passado autobiográfico; eles estão diante de mim, no meu futuro autobriográfico; atraem-me tanto a mim quanto a outros que os tocam, para saber

$$
\text { e não mais. }{ }^{26}
$$

Da mesma forma, pode-se afirmar que o "era uma vez" aponta para uma qualidade arcaica do animal escrita, como se toda a leitura fosse, sempre, um retorno a uma cena primitiva do texto que é, de si, o próprio texto:

\section{A vida eterna não existe.}

Sentou-se arranjando as saias, para assistir à produção do texto. Este texto é um texto que assiste à produção do texto.

Este texto é a cena primitiva do texto.

A mulher não existe, mas é escrita por

Assim, postos diante de uma arkhé continuamente visitada, pela "legência", pois o texto não deixa de demarcar suas erosões, suas faltas, seus traços físicos no papel, e sua esperança de que a origem seja sempre distante e próxima àquele que, ao lado do texto, faz-se seu contemporâneo, pois "a contemporaneidade tem o seu fundamento nessa proximidade com a origem, quem em nenhum ponto pulsa com mais força do que no presente." 28

Nesse sentido, a noção de presente elaborada por Heidegger (1991) nos pode auxiliar na aproximação da qualidade temporal proposta por Maria Gabriela Llansol. Segundo o filósofo, sabendo-se que "o tempo não é. Dá-Se o tempo. O dar que dá tempo determina-se a partir da proximidade que recusa retém" ${ }^{29}$, não se torna difícil compreender que sua imagem, conforme o texto de Llansol, seja tocável pela escrita, bem como sua velocidade possa ser, por esse toque, vertiginosamente alterada. A escrita torna presente o presente, o fato de que o homem é alcançado pela presença da ausência daquilo que lhe é endereçado, e que o afeta, o aborda, venha da direção passada, como a memória, venha da futura, como a esperança. Nas palavras do autor, que reproduzimos em extensão com vistas a acompanhar seu caminho reflexivo, lemos:

Na verdade, o presentar de tudo que se presenta sempre aborda o homem, sem que ele atente propriamente nisto ao presentar como tal. Mas com a mesma frequência, isto é, constantemente, também nos aborda o ausentar. De início aborda-nos de maneira tal quem muita coisa não mais se presenta de forma que conhecemos do presentar, no sentido do presente. E, con-
28. AGAMBEN. O que é o contemporâneo. p.69.

29. HEIDEGGER. Tempo e ser. p. 213

EM TESE

BELO HORIZONTE

v. 19

N. 3

SET.-DEZ. 2013

SAMUDIO. Escrever a raiz da escrita [...]

P. 24-35 
30. HEIDEGGER. Tempo e ser. p.212.

31. GUIMARÃES. A imagen soletrada. p.217. tudo, também este não-mais-presente se presenta imediatamente no seu ausentar, a saber, ao modo do "que foi" e nos aborda. Este não desaparece no anterior agora, como o puramente passado. O que foi se presenta, entretanto, à sua maneira própria. No que foi é alcançado presentar. Mas o ausentar também se endereça a nós, no sentido do ainda-não-presente, ao modo do presentar, no sentido do vir-ao-nosso-encontro. É assim que se ouve dizer: o futuro já começou; o que não é o caso, porque o futuro jamais começa primeiro, na medida em que o ausentar do ainda-não-presente já sempre, de algum modo, nos aborda, quer dizer, se presenta tão imediatamente como o que foi. No futuro, no vir-ao-nosso-encontro, é alcançado presentar. [...] encontramos no ausentar, seja aquilo que foi, seja o futuro, uma maneira de presentar e de abordar (dirigir a) que, de modo algum coincide com o presentar no sentido do presente imediato. De acordo com isso, trata-se de observar: nem todo presentar é necessariamente presente. ${ }^{30}$

Não se trata, pois, de compreender o presente como um instante destacado do passado e do futuro, como um instante entre outros dois instantes, um já dado, e um prometido. De fato, a reflexão heideggeriana permite-nos pensar que o tempo, em Maria Gabriela Llansol, tem uma qualidade de fragmento que não se propõe representar o tempo, mas a "encontrar a palavra que o acumula ou repete." ${ }^{31} \mathrm{Um}$ fragmento-presente-agora - próximo da ideia de "tempo-agora", que Agamben (2012) toma emprestada de W. Benjamin, que "reúne em uma grandiosa abreviação toda a história da humanidade" ${ }^{32}$ - que concentra, em um sentido quase espacial, o tempo, sem substância, sem face, e, agora, depois do encontro com a escrita, sem velocidade:

se eu me concentrar num fragmento do tempo não é hoje, nem amanhã,

mas se eu me concentrar num fragmento do tempo, agora,

esse fragmento revelará todo o tempo. ${ }^{33}$

Percebe-se, nesse fragmento de texto que revela uma importante compreensão a respeito de todo o texto, que as temporalidades às quais não se deve concentrar para o encontro com "todo o tempo", são "hoje" e "amanhã", de modo que, nesse fragmento-presente-agora não se abre mão de ser uma experiência com o tempo anterior, com a origem presente no agora fragmentado do texto, arkhé e promessa. Assim, o "era uma vez" tem caráter de uma existência "para sempre de uma forma breve" ${ }^{34}$, como uma fala originante que, dessa forma, nos parece, nos textos diarísticos de Llansol, estar intimamente ligada à experiência de datação.

De fato, o gesto de datar está intrinsecamente ligado à experiência de escrita, pois se trata de uma maneira de tornar presente, neste tempo de recomeço e de presentação,
32. BENJAMIN, citado por AGAMBEN, O Tempo e a História. p.123.

33. LLANSOL. O livro das comunidades. p.67.

34. LLANSOL. Ardente Texto Joshua. p.13.

EM TESE

BELO HORIZONTE

v. 19

N. 3

SET.-DEZ. 2013

SAMUDIO. Escrever a raiz da escrita [...]

P. 24-35 
35. Cf. LLANSOL. O extremo ocidental do Brabante. p.124.

36. Cf. LLANSOL. O extremo ocidental do Brabante. p.129.

37. LLANSOL. O extremo ocidental do Brabante. p.131, destaques do original.

38. CASTELLO BRANCO. Paisagens em sobreimpressão: Maria Gabriela Llansol e a Geografia dos Rebeldes. p.622.

39. LLANSOL. O extremo ocidental do Brabante. p.134, destaque no original.

40. CASTELLO BRANCO. Paisagens em sobreimpressão: Maria Gabriela Llansol e a Geografia dos Rebeldes. p.622 a escrita, a legência e os afectos que, nesses gestos, se entrecruzam pela técnica da "sobreimpressão". Segundo Maria Gabriela Llansol, sem circunscrever, de modo definitivo, o que seja tal técnica, "sobreimprimir" não diz respeito, tão-somente, à técnica textual/ discursiva de se relacionar obras antes, a "sobreimpressão" é uma forma de habitar o mundo ${ }^{35}$ e uma técnica visual, em que paisagens deslizam umas sobre outras $^{36}$, e realiza-se, no texto, como uma interpenetração, em cada cena fulgor, de vários reais. Em suas palavras:

Tudo se revelou no instante em que eu andava à procura do lugar, da geografia dessa linhagem, e deparei com o denominado estético, o entresser entre o sensível e o racional, a imaginação criadora da mística árabe, que é, talvez, de todas as manifestações de sobreimpressão, a mais portentosa. Só a partir de tais confins, olhei para trás, para os reler e para os escrever a eles, figuras definitivamente incluídas no drama europeu. ${ }^{37}$

Assim, notamos que a sobreimpressão é uma técnica que o próprio texto de Llansol realiza: técnica visual que põe a vibrar paisagens sobreimpressas, chamando aquele que lê, o "legente", a "viver, na reunião de diversos tempos, a promessa de um outro mundo." ${ }^{38} \mathrm{E}$, sabendo que o texto é uma paisagem, um aqui, "aqui poderosamente sobreimpresso"39 afirmamos, com Lucia Castello Branco, que "a escritura não é da ordem da impressão, mas da sulcagem: sobreimpressão”40.
Curiosamente, a autora afirma, a respeito de seu Diário:

a primeira imagem do Diário não é, para mim, o repouso na vida cotidiana, mas uma constelação de imagens, caminhando todas as constelações umas sobre as outras [...] Eu diria: aqui está a raiz de qualquer livro. ${ }^{41}$

Avançamos, por conseguinte, nossa compreensão acerca do tempo na "Textualidade Llansol" e afirmamos que os fragmentos de tempo assumidos pela datação, assim como a própria escrita da data, o são pela técnica de "sobreimpressão" dos tempos, de modo que, no diário de Llansol, o número é, de fato, um nome, como afirma Walter Benjamin a respeito dos números históricos ${ }^{42}$, um significante sem ser, necessariamente, referente de um passado deslocado do presente da "legência". As datas, no diário, são, pois, equivalentes, como "ambo", ao "era uma vez", o que ocorre, também, se o ofício do diário se assenta sobre um exercício de des-datar, próprio do tempo de Llansol $^{43}$.

Nesse sentido, pois, cada data seria a abertura de uma "cena fulgor", essa que é:

o logos do lugar; da paisagem; da relação; a fonte oculta da vibração e da alegria, em que uma cena - uma morada de imagens -, dobrando o espaço e reunindo diversos tempos,

procura manifestar-se $\mathrm{e}^{44}$.
41. LLANSOL. Livro de horas I: Uma data em cada mão. p.19.

42. Cf. BENJAMIN. Fragmentos (Filosofia da História e Política). p.27.

43. Cf. LLANSOL. Inquérito às quatro confidências. p.25.

4. LLANSOL. O extremo ocidental do Brabante. p.128 
45. LLANSOL. Carta ao legente. [s/p]

46. Cf. LLANSOL. Lisboaleipzig I. p.24.
Dessa forma, como "cenas fulgor", as datas, sendo assumidas, cada uma delas, como constelação de imagens, como "hoje em branco", são próprias e propícias para a escrita:

, falta-me uma flor branca para compor, com rigor, um ramo lilás. Essas, são as cores de hoje. E, para saber com rigor onde me encontro, hoje, fui ao jorna ver-lhe a data. Comparei-a, intuitivamente e em silêncio, com a mesma data dos anos anteriores. Com a perturbação de escrever, senti que a vida cresce para uma forma ou ramo, que espero ainda ver. ${ }^{45}$

Compreende-se, com isso, que o apego de Maria Gabriela Llansol ao tempo corresponde, de fato, à sua proposta de escrita - diminuir a velocidade aterradora do tempo, esvaindo-o de sua fixidez em passado-presente-futuro, dando-lhe uma qualidade no espaço do texto - e que tal experiência de fragmentação e sobreimpressão dos dias, das datas, do cotidiano, é uma maneira de presentar, no aqui e no agora da escrita, o fato de que falta uma palavra a ser dita, uma palavra que, sempre, é projeto, promessa-arcaica e arcaica-promessa, uma palavra que é feminina e que nunca se escreve e que bordeja todas as tentativas de escrever, sejam os fatos, sejam as datas. Sejam todas as obras, aproximadas e indiferenciadas ${ }^{46}$, em seu fazer, dos diários.

Finalmente, eu passei apenas pela escrita. Palavra feminina como eu. Estou a acrescentar-lhe um ramo enquanto cresce a árvore florida

\section{REFERÊNCIAS}

AGAMBEN, Giorgio. O Tempo e a História: Crítica do Instante e do Contínuo. Infância e História: Destruição da experiência e origem da história. Trad. Henrique Burigo. Belo Horizonte: UFMG 2012, p.109-126.

AGAMBEN, Giorgio. O que é o contemporâneo?. O que é o contemporâneo? E outros ensaios. Trad. Vinícius Nicastro Honesko. Chapecó: Argos, 2009, p.55-73.

ARAÚJO, Cinara de. Biografia como método: a escrita da fuga em Maria Gabriela Llansol. Belo Horizonte: Faculdade de Letras . (Tese, Doutorado em Literatura Comparada).

BENJAMIN, Walter. Fragmentos (Filosofia da História e Política). O anjo da história. Trad e org. João Barrento. Belo Horizonte: Autêntica, 2012, p.27-38.

BLANCHOT, Maurice. O desaparecimento da literatura. O livro por vir. Trad. Leyla Perrone-Moisés. São Paulo: Martins Fontes, 2005, p.285-295

BRANDÃO, Ruth Silviano. A vida escrita. Rio de Janeiro: 7Letras, 2006

Falta, pois, a escrita. 
CASTELLO BRANCO, Lucia. Nuvens de pensamento branco. CASTELLO BRANCO, Lucia; ANDRADE, Vania Baeta (orgs). Livro de asas, para Maria Gabriela Llansol. Belo Horizonte: Editora UFMG, 2007, p. 227-252.

CASTELLO BRANCO, Lucia. Paisagens em sobreimpressão: Maria Gabriela Llansol e a Geografia dos Rebeldes. In: Anais do XXIII Congresso Internacional da Associação Brasileira de Professores de Literatura Portuguesa (ABRAPLIP). 2012.

Disponível em: <http://www.abraplip.org/anais abraplip/images/ stories/Lucia\%20Castello.pdf>. Acesso em 10 dez. 2012.

GRIMM, Jacob e Wilhelm. Contos de Grimm. Trad. Zaida Maldonado. Porto Alegre: L\&PM, 2002.

GUIMARÃES, César. A imagem soletrada. Imagens da memória entre o legível e o visível. Belo Horizonte: Pós-Lit - FALE/UFMG: Editora UFMG, 1997, p.208-226.

HEIDEGGER, Martin. Tempo e ser. Conferências e Escritos Filosóficos. Trad. Ernildo Stein. São Paulo: Nova Cultural, 1991 p.203-219 (Col. Os Pensadores).

LACAN, Jacques. O seminário: Livro 20, mais ainda. Trad. M. D. Magno. Rio de Janeiro: Jorge Zahar, 2008.

LLANSOL, Maria Gabriela. Amar um cão. Cantileno. Lisboa: Relógio D'Água, 2000

LLANSOL, Maria Gabriela. Ardente Texto Joshua. Lisboa Relógio d'Água, 1998.
LLANSOL, Maria Gabriela. Um beijo dado mais tarde. Lisboa: Edições Rolim, 1991.

LANSOL, Maria Gabriela. Carta ao legente. Belo Horizonte: Breve Colóquio Intenso da Psicanálise com o texto de Maria Gabriela Llansol, 2011a (Edição Limitada).

LLANSOL, Maria Gabriela. Causa Amante. Lisboa: Relógio d'Água, 1996.

ANSOL, Maria Gabriela. Entrevistas. Belo Horizonte: Autêntica, 2011b.

LLANSOL, Maria Gabriela. O extremo ocidental do Brabante. Lisboaleipzig 1: O encontro inesperado do diverso. Lisboa: Rolim, 1994, p.124-134.

LLANSOL, Maria Gabriela. Um falcão no punho: Diario I. Belo Horizonte: Autêntica, 2011c.

LLANSOL, Maria Gabriela. Inquérito às quatro confidências: Diário III. Belo Horizonte: Autêntica, 2011d.

LLANSOL, Maria Gabriela. Lisboaleipzig 1: O encontro inesperado do diverso. Lisboa: Rolim, 1994.

LANSOL, Maria Gabriela. O livro das comunidades. Lisboa: Relógio d'Água, 1999.

LLANSOL, Maria Gabriela. Livro de Horas I: Uma data em cada mão. Lisboa: Assírio \& Alvim, 2009. 
LLANSOL, Maria Gabriela. Para que o romance não morra.

Lisboaleipzig 1: O encontro inesperado do diverso. Lisboa:

Rolim, 1994, p.116-123.

SOARES, Maria de Lourdes. O diário de Llansol: a ordem figural

do cotidiano. Andrade, Paulo de; SILVA, Sérgio Antônio (orgs).

Um corp'a'screver 2. Belo Horizonte: FALE/UFMG, 1998, p.50-58.

SOARES, Maria de Lourdes. "Um torvelinho de intensidades": O

texto-querubim e daïmon da escrita. In: Revista do Núcleo de

Estudos de Literatura Portuguesa e Africana da UFF, Vol. 4, n

8, Abril de 2012. 